\title{
BIOPROSPECÇÃO DE FUNGOS ENDOFÍTICOS ASSOCIADOS À Lippia origanoides Kunt. COM ATIVIDADE ANTIMICROBIANA.
}

\author{
$\underline{\text { Jade Ribeiro Carneiro'; }}$; Angélica Maria Lucchese²; Joelma de Souza Santos ${ }^{3}$, \\ Hianna Almeida Câmara Leite ${ }^{4}$ e Luís Fernando Pascholati Gusmão ${ }^{5}$ \\ 1. Bolsista PIBIC/CNPq, Graduando em Bacharelado em Ciências Biológicas, Universidade Estadual de Feira de \\ Santana, e-mail: rc.jade@hotmail.com \\ 2. Orientador, Departamento Exatas, Universidade Estadual de Feira de Santana, e-mail: \\ anlucc@uefs.br \\ 3. Participante do projeto, Granduanda em Farmácia, Universidade Estadual de Feira de Santana, e-mail: \\ joelma.farm@hotmail.com \\ 4. Participante do projeto, Departamento de Ciências Biológicas, Universidade Estadual de Feira de Santana, e-mail: \\ leite.hianna@gmail.com \\ 5. Participante do projeto, Departamento de Ciências Biológicas, Universidade Estadual de Feira de Santana, e-mail: \\ lgusmao@uefs.br
}

PALAVRAS-CHAVE: Lippia origanoides; endofíticos; atividade antimicrobiana.

\section{INTRODUÇÃO}

As plantas medicinais vêm sendo reconhecidas como uma fonte de fungos endofíticos produtores de metabólitos secundários de importância farmacêutica (HUANG et al, 2008). A flora brasileira dispõe de diversas espécies vegetais de aplicação medicinal, a maioria delas de ação ainda pouco caracterizada cientificamente. Tanto estas plantas, como seus endofíticos e os metabólitos produzidos por ambos, carecem de melhor investigação (SHAN et al, 2012; SIQUEIRA et al, 2011; GONG e GUO, 2009).

O gênero Lippia, o maior gênero de Verbenaceae, compreende cerca de 200 espécies, que são frequentemente utilizadas pela medicina popular brasileira (PASCUAL et al., 2001). Dentre elas a espécie Lippia origanoides Kunth., que tem um dos seus usos medicinais no tratamento de doenças associadas a microorganismos e os extratos metanólicos de folha e caule apresentam atividade antimicrobiana (PINTO et $a l, 2013)$.

Considerando a importância medicinal desta espécie e tendo em vista a ampla potencialidade de resultados promissores envolvendo a relação mutualística plantahospedeiro, este trabalho tem como objetivo a avaliação da atividade antimicrobiana frente à bactéria Gram positva Staphylococcus aureus (CCMB263 resistente a novobiocina) e à bactéria Gram negativa Escherichia coli (CCMB261 resistente a sulfonamida) e a avaliação do perfil cromatográfico de fungos endofíticos isolados de Lippia origanoides Kunth de ocorrência no estado da Bahia.

\section{MATERIAL E MÉTODOS}

\section{Coleta de material vegetal}

A espécie Lippia origanoides foi coletada em campo de cultivo no Horto Florestal da Universidade Estadual de Feira de Santana (UEFS) em agosto de 2015.

\section{Isolamento, purificação e identificação da microbiota endofítica fúngica}


Para a desinfestação do material vegetal e confirmação da desinfestação utilizouse a metodologia de Momeso, et al. (2008). Dois fragmentos vegetais de folhas ou de caules foram depositados em placas (duplicata) contendo Agar Batata Dextrose (BDA), suplementado com Cloranfenicol $[100 \mathrm{mg} / \mathrm{ml}]$. Cada colônia fúngica a iniciar crescimento foi isolada e transferida para nova placa contendo meio BDA para obtenção de culturas puras. Cada isolado recebeu um código e foi preservado. A identificação morfológica dos isolados foi realizada no Laboratório de Micologia LAMIC-UEFS.

\section{Produção dos extratos}

Os fungos foram cultivados em meio líquido (Extrato de Malte) em Shaker, a $150 \mathrm{rpm}$ e $30^{\circ} \mathrm{C}$, até zerar o nível de glicose. O micélio foi removido por filtração e os metabólitos presentes no meio líquido foram extraídos com acetato de etila. O solvente foi removido por evaporação sob pressão reduzida em evaporador rotatório, para obtenção dos extratos secos. Extratos a partir dos meios não fermentados também foram produzidos como controle.

\section{Determinação da Concentração Inibitória Mínima (CIM) e Concentração Bactericida Mínima (CBM) e Perfil químico dos extratos}

Para a determinação do CIM, foi executada microdiluição em caldo, seguindo as normas da NCCLS. Controles do meio 1x concentrado, 2x concentrado, da água, dos micro-organismos, do DMSO e do antibiótico Cloranfenicol [6 ug/uL] foram feitos. Para revelação, foi utilizado Resazurina 0,01\%. A determinação da CBM foi feita após a revelação, $1 \mathrm{uL}$ de cada poço em que não houve crescimento bacteriano foi plaqueado em placas de petri contendo Agar MH. A menor concentração em que não houve crescimento é a CBM. Para avaliar o perfil químico dos extratos e compará-los com a planta, foi realizada a cromatografia em camada delgada (CCD) em placas de sílica com os reveladores Anisaldeido - Ácido Sulfúrico (AS) para revelação de terpenos e esteroides e Reagente de Produtos naturais (NP/PEG) para revelação de fenólicos e flavonoides (WAGNER E BLADT, 2001).

\section{RESULTADOS E DISCUSSÃO}

Um total de quinze fungos foi isolado, sendo dez de caule e cinco de folha. Destes, apenas quatro não foram identificados a nivel de gênero (tabela 1). Extratos de acetato de etila de todos os isolados foram obtidos e submetidos aos testes de CIM e CBM cujos resultados se encontram na tabela 1. Os fungos três e seis, ambos pertencentes ao gênero Alternaria, apresentaram menor de CIM $(0,08 \mathrm{mg} / \mathrm{mL}$, com ação bacteriostática nesta concentração) frente ao patógeno $S$. aureus. Já o fungo onze foi o mais ativo frente ao patógeno $E$. coli com CIM de $0,8 \mathrm{mg} / \mathrm{mL}$ e ação bacteriostática nesta concentração. Os melhores resultados dos extratos frente a $S$. aureus podem ser explicados pelo fato dessa bactéria ser Gram positiva, com menor complexidade estrutural em sua parede celular, que permite uma maior permeabilidade das substâncias. Cabe destacar que fungo onze não inibiu o crescimento de S. aureus, entretanto seu extrato foi o mais ativo para E. coli.

Os diferentes resultados encontrados entre os fungos são um reflexo da composição química dos metabólitos secundários produzidos. Os produtos naturais extraídos de fungos endofíticos apresentam um amplo espectro de atividade biológica, e 
podem ser agrupados em várias categorias, dentre elas alcaloides, esteroides, terpenoides, isocumarinas, quinonas, fenilpropanoides e lignanas, fenol e ácidos fenólicos, metabólitos alifáticos, lactonas, entre outras (ZHANG et al., 2006). O resultado do CCD dos quinze extratos fúngicos e os extratos da folha e do caule de Lippia pode ser observado na figura 1 . Todos os extratos apresentaram terpenos e esteróides evidenciados pela coloração rósea, roxas e amareladas (visível) e fluorescência amarelada e azulada (UV $365 \mathrm{~nm}$ ) (figura 1, a e b) e presença de ácidos fenólicos pela fluorescência azulada e flavonoides com fluorescência amarelada, amarelo-esverdeada ou alaranjada (UV $365 \mathrm{~nm}$ ) (figura 1, c e d), entretanto em quantidades diferentes. O perfil cromatográfico dos extratos dos fungos três, cinco e seis são bem diferenciados dos outros perfis e apresentam similaridade na composição dos metabólitos e atividade antimicrobiana frente a $S$. aureus, isso pode ser uma caracteristíca do gênero Alternaria ao qual esses três microorganismos pertencem.

Tabela 1. Resultados do teste de CIM e CBM para os extratos dos fungos endofíticos isolados.

\begin{tabular}{|c|c|c|c|c|c|}
\hline & & S. at & & & \\
\hline Número & Identificação & $\begin{array}{c}\text { CIM } \\
\mathrm{mg} / \mathrm{ml}\end{array}$ & $\begin{array}{c}\mathrm{CBM} \\
\mathrm{mg} / \mathrm{ml}\end{array}$ & $\begin{array}{c}\mathrm{CIM} \\
\mathrm{mg} / \mathrm{ml}\end{array}$ & $\begin{array}{c}\mathrm{CBM} \\
\mathrm{mg} / \mathrm{ml}\end{array}$ \\
\hline 1 & Diaporthe sp. (c) & 5 & 5 & 10 & 10 \\
\hline 2 & Pestalotiopsis sp. (c) & 5 & 10 & 10 & 10 \\
\hline 3 & Alternaria sp. (c) & 0,08 & 0,16 & 5 & 10 \\
\hline 4 & Phoma-like (c) & 10 & 10 & 10 & - \\
\hline 5 & Alternaria sp. (c) & 2,5 & 2,5 & 10 & - \\
\hline 6 & Alternaria sp. (c) & 0,08 & 0,16 & 5 & 5 \\
\hline 7 & Micélio estéril (c) & 5 & 5 & 5 & 10 \\
\hline 8 & Dreschlera sp. (c) & 0,625 & 1,25 & 5 & 10 \\
\hline 9 & Phoma-like (c) & 5 & 10 & 5 & 10 \\
\hline 10 & $\begin{array}{l}\text { Fusarium sp. (c) } \\
\text { Micélio estéril (f) }\end{array}$ & 10 & 10 & 10 & 10 \\
\hline 11 & Ascomiceto com anamorfo & $\mathrm{R}$ & $\mathrm{R}$ & 0,8 & 10 \\
\hline 12 & Phoma-like (f) & 10 & 10 & 10 & 10 \\
\hline 13 & Ascomiceto (f) & 5 & 10 & 5 & 10 \\
\hline 14 & Micélio estéril (f) & 1,25 & 5 & 2,5 & 5 \\
\hline 15 & Myrmecridium schulzeri(f) & 10 & 10 & 10 & 10 \\
\hline 16 & Caule & 2,5 & 2,5 & 10 & 10 \\
\hline 17 & Folha & 2,5 & 2,5 & 10 & 10 \\
\hline
\end{tabular}

Legenda: (c) corresponde a isolamento do caule e (f) isolamento da folha. A concentração inicial para todos os extratos foi de $10 \mathrm{mg} / \mathrm{ml}$. R - resistente: Não inibiu o crescimento bacteriano até a maior concentração testada. ( - ) indica que não houve ação bactericida, apenas bacteriostática. 


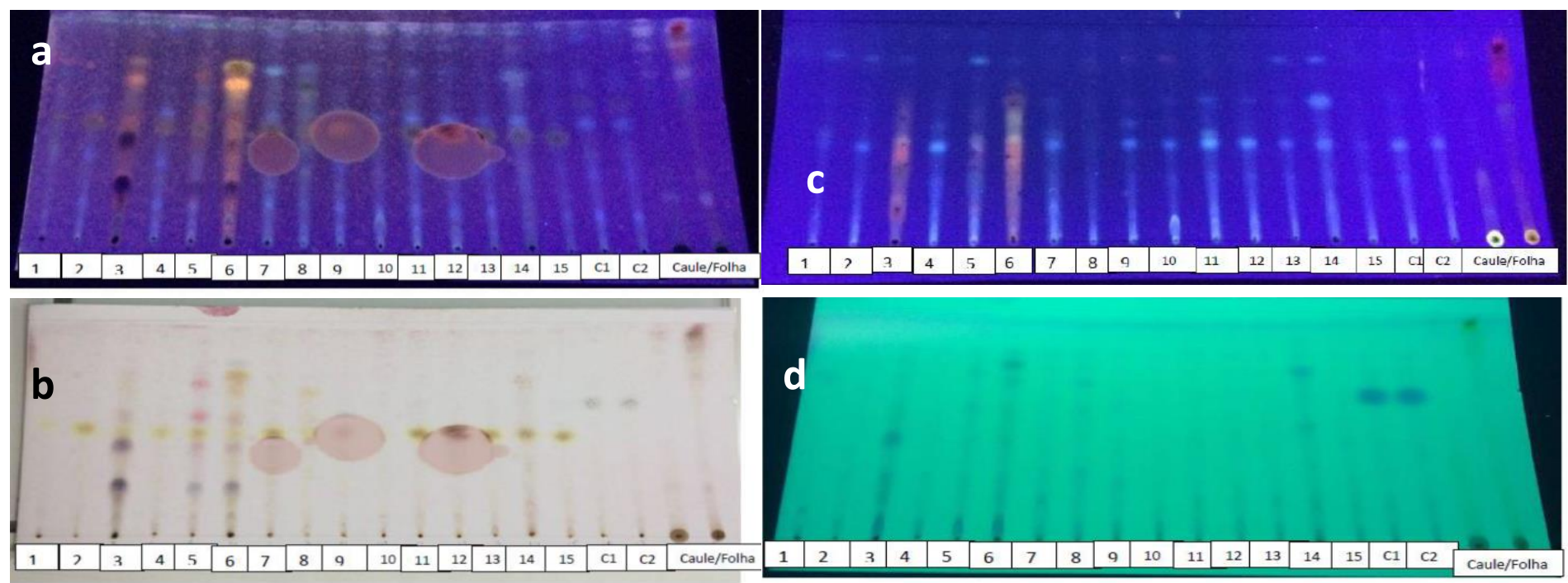

Figura 1. Cromatografia em Camada Delgada dos extratos dos fungos isolados e extratos do caule e da folha de Lippia origanoide.s a) CCD revelada com AS na luz UV365nm, b) CCD revelada com AS na luz visível, c) CCD revelada com NP/PEG na luz UV365nm e d) CCD revelada com NP/PEG na luz germicida. Os números dos extratos correspondem aos números dos fungos da tabela 1. Proporção dos solventes: hexano acetona (1:1).

\section{CONSIDERAÇÕES FINAIS}

Os fungos endofíticos três e seis (Alternaria sp), oito (Dreschlera $s p$ ) e onze (não identificado) se revelaram fontes promissoras de metabólitos secundários ativos. Futuros trabalhos serão necessários para isolamento e identificação desses compostos.

\section{REFERÊNCIAS}

GONG, L.; GUO, S. 2009. Endophytic fungi from Dracaena cambodiana and Aquilaria sinensis and their antimicrobial activity. African Journal of Biotechnology. 8(5).

HUANG, W.Y., CAI, Y.Z. and HYDE, K.D., CORKE, H.; SUN, M.(2008). Biodiversity of endophytic fungi associated with 29 traditional Chinese medicinal plants. Fungal Diversity 33: 61-75.

MOMESSO, L. S.; KAWANO, C. Y.; RIBEIRO, P. H.; NOMIZO, A.; GOLDMAN, G. H.; PUPO, M. T. 2008. Chaetoglobosinas produzidas por Chaetomium globosum, fungo endofítico associado à Vigueira robusta (Asteraceae). Química Nova.

PASCUAL, M.E. et al. 2001. Lippia: traditional uses, chemistry and pharmacology: a review. Journal of Ethnopharmacology. 76: 201-214.

PINTO, C. P. et al. 2013. Antimicrobial Activity of Lippia Species from the Brazilian Semiarid Region Traditionally Used as Antiseptic and Anti-Infective Agents. EvidenceBased Complementary and Alternative Medicine. 2013: 6.

SHAN, T. et al. 2012. Antibacterial activity of the endophytic fungi from medicinal herb, Macleaya cordata. African Journal of Biotechnology. Vol. 11(19): 4354-4359.

SIQUEIRA, V. M., CONTI, R., DE ARAÚJO, J. M., SOUZA-MOTTA, C. M. 2011. Endophytic fungi from the medicinal plant Lippia sidoides Cham. and their antimicrobial activity. Symbiosis. 53(2): 89-95.

WAGNER, H.; BLADT, S. 2001. Plant Drug Analysis, a thin layer chromatografy atlas. Springer. Second edition.

ZHANG, H. W.; SONG, Y. C.; TAN, R. X. 2006. Biology and chemistry of endophytes. Natural product reports. 23(5): 753-771. 